\title{
Development and testing of a quantitative food frequency questionnaire for use in Kerala, India
}

\author{
James R Hebert ${ }^{1, *}$, Prakash C Gupta ${ }^{2}$, Ramesh B Bhonsle ${ }^{2}$, PR Murti ${ }^{2,3}$, Hemali \\ Mehta $^{2}$, Florence Verghese ${ }^{2}$, Mira Aghi ${ }^{2}$, Kamala Krishnaswamy ${ }^{4}$ and Fali S Mehta ${ }^{2}$ \\ 'Division of Preventive and Behavioral Medicine, Department of Medicine, University of \\ Massachusetts Medical School, 55 Lake Avenue, Worcester, MA 01655, USA: ${ }^{2}$ Epidemiology \\ Research Unit, Tata Institute of Fundamental Research, Homi Bhabha Road, Bombay 400005, India: \\ ${ }^{3}$ Currently affiliated with the Faculty of Medical Sciences, University of the West Indies, Champa \\ Fleurs, Trinidad and Tobago, West Indies: ${ }^{4}$ National Institute of Nutrition, Indian Council of Medical \\ Research, Hyderabad 500007, India
}

Submitted 30 Januory 1998: Accepted 8 April 1998

\begin{abstract}
Abstroct
Objective: To develop and test a food frequency questionnaire (FFQ) for use in rural areas of Kerala, India.

Design: Based on food use and market surveys of the study area, a quantitative 81item interviewer-administered FFQ was developed. A validation study was conducted consisting of 24-h diet recalls (24HR) administered on 8 days randomly selected over an entire year and two administrations of the FFQ, one at the beginning of the 1-year period and the other at the end. FFQ and 24HR-derived nutrient scores were compared using correlation and regression analyses and by examining differences in the nutrient scores.

Setting: Rural villages in Ernakulum district, Kerala, South India.

Subjects: In each of 30 households, the male head of household and female food preparer were enrolled.

Results: Pearson (parametric) correlation coefficients $\left(r_{\mathrm{p}}\right)$ averaged about 0.50 in comparing nutrient scores derived from the $24 \mathrm{HR}$ with those from the first FFQ and about 0.55 in comparing the second FFQ. On average, Spearman correlation coefficients $\left(r_{s}\right)$ were slightly lower than the $r_{\mathrm{p}}$ in comparing the scores derived from the first FFQ, but virtually identical for the second FFQ. Regression analyses indicated better agreement in the comparison of the $24 \mathrm{HR}$-derived scores with the first FFQ than the second FFQ. Difference scores, however, tended to be larger in comparing the first FFQ scores with the $24 \mathrm{HR}$.

Conclusions: This FFQ produces results broadly comparable to those used in Europe and North America, indicating its suitability for comparing exposures within a snudy population in reference to health-related endpoints.
\end{abstract}

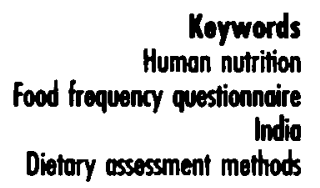

Koywords Indig tio
The food frequency questionnaire (FFQ) has become the method of choice for dietary assessment in most large-scale epidemiological studies ${ }^{1}$. Despite limitations of structured questionnaires of this type $e^{2,3}$, a major advantage of the FFQ is its feasibility for establishing long-term habitual dietary intake ${ }^{1}$. Thus it was the method of choice for examining the role of nutritional factors in oral precancer, in India.

Although various FFQs are used widely in epidemiological studies in the West ${ }^{1,4,5}$, none have been developed and tested in India. Using an FFQ for collecting dietary data in India was especially attractive due to: relatively large inter-relative to intra- (mainly day-to-day) person variability ${ }^{6}$; a shorter questionnaire (under 100 food items) could make querying respondents easier ${ }^{7,8}$; and smaller chance of response bias due to prior knowledge of diet-disease relationships. Also, in a separate study it was established that rural Indians were more accurate in estimating weights and volumes of food items than were more highly educated individuals in the West?

In observational epidemiological studies of diet or nutrition reported from India, the dietary assessment has consisted of check lists for different foods and food categories $^{10-12}$. Thus far, no epidemiological study employing a validated FFQ has been reported from India. Therefore, to achieve the goal of nutrient estimation, the first task was to develop and test an FFQ appropriate to the target population. As part of the on-going study of oral cancer and precancer ${ }^{13}$, this 
study was conducted in the same three areas of India: Ernakulam district in Kerala; Srikakulam district in Andhra Pradesh; and Bhavnagar district in Gujarat. There being major differences in foods eaten in different parts of India, it was necessary to develop a separate FFQ for each region. This article describes the development of the FFQ in Ernakulam district, Kerala state, for a variety of nutrients that plausibly could be related to oral cancer and precancer and presents results of a validation study to test the FFQ.

\section{Methods}

A considerable amount of relevant prior information was available for developing and testing an FFQ. This consisted of a database with 592 food items commonly consumed in India including almost all food items consumed in the target area. It provided values of 30 nutrients including macronutrients and some micronutrients ${ }^{14}$. In addition, we had access to a report on a number of diet surveys ${ }^{8}$.

As the first step in developing the FFQ, food lists were prepared by interviewing 201 individuals representing the major groups in the study area regarding the food items typically consumed, including ingredients of prepared items, condiments and spices. Cross-checking these food lists with the nutrient database $^{14}$, it was confirmed that the list of food items accounted for $>95 \%$ of the intake of the target nutrients ( $\beta$-carotene, ascorbic acid, thiamine, riboflavin, calcium, zinc, copper, iron and sodium). This was based on the concentrations of nutrients in the named food items and the rate at which they were eaten, based on our survey data.

A prototype FFQ developed from this food list was pilot-tested by visiting family units representative of the target population. The objective was to determine completeness of the list and to collect recipes for prepared items included in the FFQ. In reviewing the recipe data, relatively large differences in the concentration of ingredients and, concomitantly, nutrients in the recipe content of certain preparations were observed. For example, in $100 \mathrm{~g}$ of prepared pulse curries the concentration of zinc ranged from 0.30 to $1.15 \mathrm{mg}$. For iron, the range was $1.39-3.41 \mathrm{mg}$ and for copper $0.13-0.60 \mathrm{mg}$. To some extent, these differences appeared to be associated with religion and economic status, as might be expected ${ }^{15,16}$. For example, the $\beta$-carotene content per $100 \mathrm{~g}$ of prepared sambhar, a spicy lentil soup dish typically consumed throughout southern India, was $157 \mu \mathrm{g}$ in lower economic status Christians and $270 \mu \mathrm{g}$ in upper economic status Christians. The zinc concentration per $100 \mathrm{~g}$ of sambhar was $0.88 \mathrm{mg}$ in Muslims and $1.49 \mathrm{mg}$ in Christians. Therefore, for final construction of the recipe database for the $F F Q$, representative recipes were collected for each prepared food according to the three major religions (Hindu, Muslim and Christian) and for three economic classes: lower, middle and higher. Because objective data on family wealth and income were difficult to obtain, type of house construction was used as a proxy for economic status. High status was defined as possessing a concrete or tiled house with more than five rooms and all basic (e.g. indoor plumbing) and many modern amenities (including a refrigerator). Middle status was defined as five or fewer rooms in a home with plastered walls and floors, all basic but few modern amenities. Low status individuals were those who dwelled in mud brick houses with thatched roofs and unplastered walls and floors and having neither basic nor modern amenities.

\section{Description and administration of tbe $F F Q$}

The FFQ contained 81 food items, of which 65 were prepared from two or more ingredients. Twenty-nine of these food items differed primarily on the main ingredient (e.g. eggplant curry and squash curry) These preparations were similar in terms of nutrient content and method of preparation, and they represented similar dietary choices. Therefore, these items were further categorized according to the main ingredients and assigned subcodes. There were 119 subcodes for these 29 items. An individual was asked to respond only to these 29 items on the FFQ, and not to specific subcoded items. When nutrient scores were computed from the responses to these 29 items they were weighted by the population average proportional consumption of the subcoded foods.

For each food item on the FFQ, the average frequency of consumption over the past year and the normal portion size typically eaten by the respondent was ascertained. For items that were available only seasonally, such as fruits and certain vegetables, the frequency of consumption was recorded only for the season in which it was consumed. This obviated the need for the respondent or the interviewer to undertake the tedious and error-prone exercise of computing the yearly average intake for seasonal items.

During the year of the validation study, data were collected to establish seasonal availability of food items and to standardize weight equivalence for volume, diameter size and piece designations. For a seasonally available item, the proportion of the year that it was available became a multiplier in the algorithm for computing nutrient scores.

Portion size estimation was undertaken using volume measures, circular measures, numbers and linear measures. A set of 12 metal vessels (Fig. 1) ranging in size from 1547 to $32 \mathrm{~cm}^{3}$ was used as an aid to estimating volumes. In addition, two spoons were used to estimate very small quantities $\left(13\right.$ and $8 \mathrm{~cm}^{3}$ ). Similar vessels were reported to have been used in 


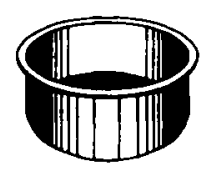

c1

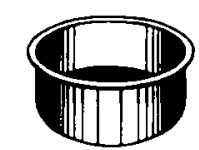

C2

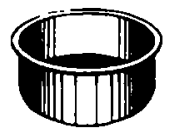

[3

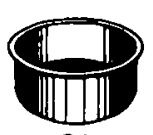

(4

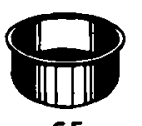

C5

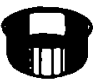

C10
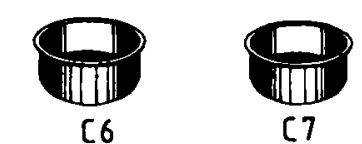

C7
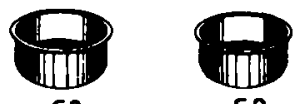

CB

[9
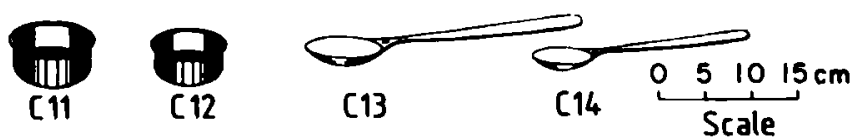

Fig. 1 Stainless steel vessels and spoons used to assist participants in estimating volumes of ingredients used in prepared foods and portion sizes of foods consumed

earlier studies ${ }^{17}$. For approximately circular items such as chappati or dosai, a set of ten circular models was developed ranging from 24.0 to $3.7 \mathrm{~cm}$ in diameter. Some items such as bread slices and salty snacks were recorded as integer multiples of standard portion sizes. Most fruits were recorded in three sizes: small, medium or large. Items such as fried fish were recorded in a single linear measure. Volumetric estimation was based on the three-dimensional measurements associated with the food's length or surface area as ascertained in surveys of local food vendors and eating establishments.

In the study region, 30 households were selected to represent the nine specific religious-economic classes. In each household, the male head of household and female food preparer were enrolled. To be eligible, the male had to be a tobacco user (because that was the target group for the epidemiological study in which the FFQ was to be used) and both the male and female had to have no dietary restrictions, be compos mentis, be permanent residents of the area and be available over the entire next year for interviewing (no absences planned). The FFQ was administered twice, once at the beginning and again at the end of the 1-year validation study period.

\section{The 24-b diet recall interview}

Normally, nutrient intakes estimated from an FFQ are compared to those derived from multiple days of food diaries or 24-h diet recall interviews $(24 \mathrm{HR})^{1,18}$. Because a part of the study population was illiterate, keeping food diaries was not an available option. Therefore, we chose the $24 \mathrm{HR}$, which a number of studies also have found to produce the lowest overall variance ${ }^{19-21}$, as the reference standard for validating this FFQ.

The 24HR was an open-ended, prompted interview conducted by a qualified research dietitian. The reference period for the $24 \mathrm{HR}$ was the day prior to the day of the interview. The $24 \mathrm{HRs}$ were administered on 8 randomly selected days, but avoiding days immediately following important religious and social festivals. To account for variations in diet, intake days were selected to represent the three main seasons of the year and weekdays as well as weekends. Interviews were conducted so as to take the respondent through the recall process in direct chronological order from the first food encounter of the day to the last.

When the respondent was a female and the food was a home-made item, then recipe information was collected from her. If the selected female respondent to the $24 \mathrm{HR}$ had not prepared the food, the recipe was obtained from the person in the same household who had prepared the food. Thus, recipe information was collected for each food item reportedly consumed in each of eight $24 \mathrm{HR}$, even if the food item was prepared more than once. When a respondent was not able to identify a prepared food item by name, only the main ingredients and the type of preparation (e.g. curry or dry) were identified. An appropriate name was then assigned to the preparation by the interviewer. An attempt was made to alter the order of interviewing the male and female within a household during successive administrations of the $24 \mathrm{HR}$.

In all instances, the interview was held only with the interviewee, with no one else present. In Kerala, houses typically are sited on moderate to large compounds separated from each other by man-made barriers or natural ones consisting of coconut palm and other types of trees. Perhaps owing to a high literacy rate and other unique attributes of the social structure $^{22,23}$, there tends to be an orderly environment for interviewing. Even in lower economic classes, where spacious compounds are not the rule, it is easier to control the interview than it might be in other parts of India. Once the dietitian explained the purpose of the study and the need to conduct the interview in private, there was complete cooperation from family members and neighbours. 


\section{Computing nutrient scores}

Computation of nutrient scores on the basis of food items consumed required recipes with a listing of ingredients and the quantities used. As stated earlier, there could be large differences in relative quantities of ingredients for the same food item. Therefore, recipes were categorized according to each of three religious and socioeconomic groups. To obtain good representation, the target was to obtain three recipes from each of the nine religious and socioeconomic groups. Some food items were rarely consumed by certain groups, resulting in fewer than three recipes per group. There were on the average 23 , and not 27 , recipes for each food item. In total, there were 1508 recipes in the recipe database, each recipe containing on average seven ingredients.

For all items listed as raw ingredients in the recipe records, the edible portion of each was weighed separately on a balance whose minimum capacity was $5 \mathrm{~g}$. To minimize errors cup measures in excess of $200 \mathrm{~g}$ were used. Thus, the weight equivalences of all ingredients estimated as volumes were established and, from this, the proportional weight of each raw ingredient in each preparation was derived. Estimates were made of the weight and volume of prepared foods to take into account changes in the water content, and therefore their nutrient concentrations, as a consequence of cooking; e.g. rice would tend to absorb a large quantity of water while succulent vegetables would tend to lose water. For items reported in circular sizes, three samples of the size (diameter) typically eaten were weighed and the average taken. For items reported in numbers, the weight of the item was averaged, again from three samples. For fruits, equivalent gram weights were computed from either cup measures or relative sizes based on the standard definitions of small, medium or large.

To derive nutrient data from the $24 \mathrm{HR}$, the gram weight equivalent estimated from portion size information was multiplied directly by the nutrient values in the nutrient database. For computing nutrient scores from prepared items on the $24 \mathrm{HR}$, the procedure was to use, in order of availability: (1) the recipe corresponding to the household; (2) the average recipe for the religion-economic class groups; or (3) the average recipe for the entire study population if the item was prepared outside the home. As for whole foods, food items comprising a recipe were multiplied directly by the corresponding nutrient value in the nutrient database.

Computing nutrient scores from the FFQ was more complex, since several recipes could be available for a single food item. Therefore the most appropriate recipe according to socioreligious classification was used. If a recipe for an appropriate socioeconomic category was not available, then the average recipe for the validation study population was used. For 36 items representing a single type of prepared dish, i.e. having no subcodes, the simple arithmetic average of the recipes was used. For items representing several types of dishes varying on their main ingredient, i.e. those having subcodes, recipes were weighted by the rate that foods comprising the subcode were consumed in the target population. The recipes formed the main database for linking the foods listed on the FFQ to the nutrients listed in the National Institute of Nutrition database. Appropriate adjustments were made for seasonally available food items and for specific ingredients in a recipe.

\section{Statistical metbods}

Simple univariate statistics of nutrient scores derived from both the multiple $24 \mathrm{HR}$ and the FFQ were computed to identify out-of-range responses and to examine adherence in testing the statistical assumptions involved in testing concordance between the two sets of nutrient scores. Pearson (parametric) and Spearman (rank order) correlation coefficients were computed, as is the standard practice in studies of dietary assessment methods ${ }^{1,4,21}$. De-attenuation of the correlation coefficients was done for correcting within-person variability by using standard methods ${ }^{24,25}$. Due to the fact that women and men were sampled in pairs, the intraclass correlation coefficient was computed by household to determine to what extent their responses were correlated.

Because correlation may not be adequate for representing agreement across methods, the differences between individuals' FFQ and 24HR-derived nutrient scores also were examined, as has been suggested previously ${ }^{26-28}$. Linear regression was also used to assess the agreement between the FFQ-derived nutrient scores and arithmetic average of those obtained from the 8 days of $24 \mathrm{HR}$. One specific hypothesis was to test whether the slope of the regression line was 1.0 (indicating a perfect agreement between the nutrient scores derived from the two methods).

\section{Results}

No data collected were deemed to represent obviously erroneous values. Therefore, all data shown and discussed here include every response from each individual enrolled in the study. Descriptive statistics of the study population are shown in Table 1 . Nutrition data shown are based on the average of the 8 days of $24 \mathrm{HR}$. In general, results of the descriptive analyses are what we would expect, with a few exceptions. Individuals in this group, especially women, were very well educated by Indian standards, though of average educational attainment for Kerala ${ }^{29}$. Women consumed 
Table 1 Descriptive data for the Food Frequency Questionnaire Validation Study, Ernakulam District, Kerala, India, 1993-94

\begin{tabular}{|c|c|c|}
\hline & $\begin{array}{l}\text { Males } \\
n=30\end{array}$ & $\begin{array}{c}\text { Females } \\
n=30\end{array}$ \\
\hline $\begin{array}{l}\text { Age* } \\
\text { Education }\end{array}$ & $52.6(10.9)$ & $43.2(13.6)$ \\
\hline $\begin{array}{l}\text { illiterate } \\
\text { primary } \\
\text { middle } \\
\text { high } \\
\text { college }\end{array}$ & $\begin{array}{l}10.0 \% \\
33.3 \% \\
20.0 \% \\
26.7 \% \\
10.0 \%\end{array}$ & $\begin{array}{l}23.3 \% \\
16.7 \% \\
10.0 \% \\
40.0 \% \\
10.0 \%\end{array}$ \\
\hline $\begin{array}{l}\text { Religion } \\
\text { Hindu } \\
\text { Muslim } \\
\text { Christian }\end{array}$ & $\begin{array}{l}33.3 \% \\
33.3 \% \\
33.3 \%\end{array}$ & $\begin{array}{l}33.3 \% \\
33.3 \% \\
33.3 \%\end{array}$ \\
\hline $\begin{array}{l}\text { Occupation } \\
\text { business/professional } \\
\text { farming/merchandise } \\
\text { skilled labour } \\
\text { secretarial/clerical } \\
\text { unskilled/self employed } \\
\text { householder }\end{array}$ & $\begin{array}{r}6.7 \\
36.7 \\
16.7 \\
- \\
20.0 \\
20.0\end{array}$ & $\begin{array}{r}- \\
3.3 \\
- \\
3.3 \\
10.0 \\
83.3\end{array}$ \\
\hline $\begin{array}{l}\text { Nutritional variables* } \\
\text { total energy }\left(\mathrm{kcal}^{*} \text { day }^{-1}\right) \\
\text { total fat ( }\left(\mathrm{g} \text { day }^{-1}\right) \\
\text { fat (\% energy) }\end{array}$ & $\begin{array}{c}2488(613) \\
61.9(16.8) \\
22.7(5.0)\end{array}$ & $\begin{array}{c}1940(552) \\
42.6(17.9) \\
19.1(5.5)\end{array}$ \\
\hline $\begin{array}{l}\text { fibre }\left(\mathrm{g} \mathrm{day}^{-1}\right) \\
\text { iron }\left(\mathrm{mg} \mathrm{day}^{-1}\right)\end{array}$ & $\begin{array}{r}8.6(3.2) \\
15.3(4.4)\end{array}$ & $\begin{array}{r}7.4(3.3) \\
11.8(4.0)\end{array}$ \\
\hline $\begin{array}{l}\left.\text { sodium (mg day }{ }^{-1}\right) \\
\text { copper }\left(\mathrm{mgday}^{-1}\right) \\
\text { zinc }\left(\mathrm{mg} \mathrm{day} \mathrm{day}^{-1}\right) \\
\left.\text { calcium (mgday }{ }^{-1}\right) \\
\text { ascorbic acid }\left(\mathrm{mg} \mathrm{day}^{-1}\right) \dagger\end{array}$ & $\begin{array}{c}249(106) \\
1.22(0.48) \\
6.28(2.25) \\
843(252) \\
58.3(24.1)\end{array}$ & $\begin{array}{c}136(77) \\
0.98(0.39) \\
5.24(1.96) \\
519(183) \\
51.1(28.2)\end{array}$ \\
\hline $\begin{array}{l}\beta \text {-carotene }\left(\mu \mathrm{gday}{ }^{-1}\right) t \\
\text { thiamine }\left(\mathrm{mg} \mathrm{day}^{-1}\right)\end{array}$ & $\begin{array}{r}1094(401) \\
1.45(0.49)\end{array}$ & $\begin{array}{l}695(413) \\
1.12(0.40)\end{array}$ \\
\hline riboflavin (mg day ${ }^{-1}$ ) & $1.06(0.35)$ & $0.67(0.25)$ \\
\hline
\end{tabular}

"Values are mean and standard deviation in parentheses. Values are percentage of sample with the attribute. Nutritional variables are based on the average of 8 days of $24 \mathrm{HR}$ diet recalls.

tThe distribution of vitamin $C$ and $\beta$-carotene are non-normal. diets with lower overall energy content (about 78\% that of men), as is the norm. Consumption of most nutrients was roughly proportional to the ratio of energy intake among men and women except for $\beta$-carotene, sodium and calcium, the reported intakes of which were much lower in women. Intake of iron was moderately high while that of fibre was low. It appears that both of these findings can be traced to the same sources, high intake of rice and rice products (accounting for $3.2 \mathrm{mg} \mathrm{day}^{-1}$ ); meat $(2.6 \mathrm{mg}$ ) and dairy products $(1.0 \mathrm{mg})$. The total intake of foods in these categories represented exactly half of total average iron intake but contributed just about nothing to intake of dietary fibre.

Difference scores, obtained by subtracting the FFQderived scores from the $24 \mathrm{HR}$-derived score are shown in Table 2. In general, these were much smaller when comparing nutrient scores derived from the $24 \mathrm{HR}$ with those from 1-year FFQ than with those derived from the baseline FFQ.

Table 3 shows the Pearson product moment (parametric) and Spearman rank order correlation coefficients. The coefficients shown are without de-attenuation. With 8 days of $24 \mathrm{HR}$ per subject, the de-attenuated coefficient was only slightly larger than the raw coefficients shown (usually under 0.02 larger). The Spearman correlation coefficient was larger than the Pearson correlation coefficient about half of the time, indicating that the FFQ was about as good at rank ordering individuals relative to the $24 \mathrm{HR}$ as it was in providing simple linear agreement. There was no clear pattern evident regarding the temporal ordering of the FFQ (baseline versus 1-year), although Spearman correlation coefficients appeared more similar to Pearson product moment correlation coefficients in the 1-year FFQ comparisons. Analyses stratified by

Table 2 Difference scores - Food Frequency Questionnaire Validation Study, Emakulam District, Keral, India, 1993-94*

\begin{tabular}{|c|c|c|c|c|c|c|}
\hline \multirow[b]{2}{*}{$\begin{array}{l}\text { Nutritional } \\
\text { variables }\end{array}$} & \multicolumn{3}{|c|}{ Baseline FFQ } & \multicolumn{3}{|c|}{ 1-year FFQ } \\
\hline & $\underset{\mathrm{FFQ}^{*}}{\Delta 24 \mathrm{HR}}$ & SD & $P$-value & $\underset{\mathrm{FFQ}^{*}}{\Delta 24 \mathrm{HR}}$ & SD & $P$-value \\
\hline $\begin{array}{l}\left.\text { Total energy (kcal day }{ }^{-1}\right) \\
\left.\text { Total fat (g day }{ }^{-1}\right) \\
\text { Fat (\% energy) }\end{array}$ & $\begin{array}{r}-726 \\
-8.9 \\
2.2\end{array}$ & $\begin{array}{r}904 \\
3.5 \\
7.8\end{array}$ & $\begin{array}{l}0.0001 \\
0.02 \\
0.020\end{array}$ & $\begin{array}{l}-6 \\
9.3 \\
3.8\end{array}$ & $\begin{array}{r}500 \\
24.6 \\
7.6\end{array}$ & $\begin{array}{l}0.92 \\
0.07 \\
0.0002\end{array}$ \\
\hline Fibre $\left(g_{\text {day }}^{-1}\right)$ & -1.0 & 3.8 & 0.03 & 1.4 & 3.7 & 0.006 \\
\hline $\begin{array}{l}\left.\text { Iron (mg day }{ }^{-1}\right) \\
\text { Sodium (mg day-1) } \\
\left.\text { Copper (mg day }{ }^{-1}\right)\end{array}$ & $\begin{array}{l}-2.7 \\
-51 \\
-0.36\end{array}$ & $\begin{array}{c}5.2 \\
118 \\
0.56\end{array}$ & $\begin{array}{l}0.0001 \\
0.001 \\
0.0001\end{array}$ & $\begin{array}{l}1.7 \\
1.3 \\
0.01\end{array}$ & $\begin{array}{l}4.3 \\
97 \\
0.36\end{array}$ & $\begin{array}{l}0.005 \\
0.92 \\
0.84\end{array}$ \\
\hline $\begin{array}{l}\left.\text { Zinc (mg day }{ }^{-1}\right) \\
\text { Calcium (mg day } \\
\text { Ascorbic acid }\left(\mathrm{mgday}^{-1}\right) \mathrm{t}\end{array}$ & $\begin{array}{l}-2.29 \\
-96 \\
-0.33\end{array}$ & $\begin{array}{c}3.18 \\
299 \\
0.64\end{array}$ & $\begin{array}{l}0.0001 \\
0.02 \\
0.0002\end{array}$ & $\begin{array}{c}-0.56 \\
126 \\
0.10\end{array}$ & $\begin{array}{c}1.57 \\
265 \\
0.52\end{array}$ & $\begin{array}{l}0.01 \\
0.0008 \\
0.14\end{array}$ \\
\hline$\beta$-carotene $\left(\mu \mathrm{g} \mathrm{day}^{-1}\right) \dagger$ & -0.80 & 0.76 & 0.0001 & -0.31 & 0.54 & 0.0001 \\
\hline Thiamine (mg day ${ }^{-1}$ ) & -0.49 & 0.58 & 0.0001 & -0.05 & 0.38 & 0.32 \\
\hline Riboflavin (mg day ${ }^{-1}$ ) & -0.30 & 0.39 & 0.0001 & -0.02 & 0.30 & 0.55 \\
\hline
\end{tabular}

"The average difference obtained in subtracting each individual's FFQ-derived score from the average of that person's $24 \mathrm{HR}$. 
Table 3 Results of correlation and regression analyses - Food Frequency Questionnaire Validation Study, Emakulam District, Kerala, India, $1993-94^{*}$

\begin{tabular}{|c|c|c|c|c|c|c|c|c|}
\hline \multirow[b]{3}{*}{ Nutritional variables } & \multicolumn{4}{|c|}{ Correlation } & \multicolumn{4}{|c|}{ Regression } \\
\hline & \multicolumn{2}{|c|}{ Pre } & \multicolumn{2}{|c|}{ Post } & \multicolumn{2}{|c|}{ Pre } & \multicolumn{2}{|c|}{ Post } \\
\hline & $r_{p}$ & $r_{s} \dagger$ & $r_{p}$ & $r_{\mathbf{s}} \dagger$ & $b \ddagger$ & $\left(S \theta_{b}\right)$ & $b+$ & $\left(S e_{b}\right) \S$ \\
\hline Total energy ( $\mathrm{kcal} \mathrm{day}^{-1}$ ) & 0.44 & 0.59 & 0.62 & 0.54 & 0.66 & $(0.18)$ & 0.61 & $(0.10)$ \\
\hline $\begin{array}{l}\text { Total fat }\left(\mathrm{g} \mathrm{day}^{-1}\right) \\
\text { Fat ( } \% \text { energy) }\end{array}$ & $\begin{array}{l}0.43 \\
0.35\end{array}$ & $\begin{array}{l}0.46 \\
0.35\end{array}$ & $\begin{array}{l}0.24 \\
0.23\end{array}$ & $\begin{array}{l}0.32 \\
0.34\end{array}$ & $\begin{array}{l}0.64 \\
0.43\end{array}$ & $\begin{array}{l}(0.18) \\
(0.15)\end{array}$ & $\begin{array}{l}0.27 \\
0.28\end{array}$ & $\begin{array}{l}(0.15) \\
(0.16)\end{array}$ \\
\hline Fibre $\left(g_{\text {day }}{ }^{-1}\right)$ & 0.60 & 0.62 & 0.30 & 0.40 & 0.77 & $(0.14)$ & 0.39 & $(0.17)$ \\
\hline Iron (mg day ${ }^{-1}$ ) & 0.55 & 0.57 & 0.49 & 0.61 & 0.72 & $(0.15)$ & 0.51 & $(0.12)$ \\
\hline Sodium (mg day ${ }^{-1}$ ) & 0.62 & 0.67 & 0.58 & 0.70 & 0.86 & $(0.14)$ & 0.58 & $(0.11)$ \\
\hline Copper (mg day ${ }^{-1}$ ) & 0.50 & 0.55 & 0.53 & 0.60 & 0.62 & $(0.14)$ & 0.46 & $(0.10)$ \\
\hline Zinc $\left(\mathrm{mg}\right.$ day $\left.^{-1}\right)$ & 0.33 & 0.44 & 0.61 & 0.54 & 0.49 & $(0.18)$ & 0.54 & $(0.09)$ \\
\hline Calcium (mg day ${ }^{-1}$ ) & 0.50 & 0.54 & 0.42 & 0.46 & 0.58 & $(0.13)$ & 0.33 & $(0.10)$ \\
\hline Ascorbic acid $\left(\mathrm{mg} \mathrm{day}^{-1}\right) \|$ & 0.32 & 0.37 & 0.53 & 0.52 & 0.32 & $(0.12)$ & 0.64 & $(0.14)$ \\
\hline$\beta$-carotene $\left(\mu \mathrm{g} \mathrm{day}^{-1}\right) \|$ & 0.45 & 0.37 & 0.53 & 0.49 & 0.52 & $(0.13)$ & 0.52 & $(0.11)$ \\
\hline Thiamine (mg day ${ }^{-1}$ ) & 0.52 & 0.55 & 0.55 & 0.51 & 0.73 & $(0.16)$ & 0.51 & $(0.10)$ \\
\hline Riboflavin (mg day ${ }^{-1}$ ) & 0.61 & 0.64 & 0.61 & 0.67 & 0.83 & $(0.14)$ & 0.60 & $(0.11)$ \\
\hline
\end{tabular}

-Values are shown for the comparison of the baseline (pre) and 1-year (post) FFQ in relation to the average of.the eight 24HR recalls. tSpearman rank correlation based on the rank order of the data.

$\$$ The regression coefficient is obtained in regressing the specified FFQ-derived nutrient score on the 24HR-derived nutrient score.

§tandard error of the regression coefficient.

IValues for this nutrient have been log-transformed $(\mathrm{In})$ to normalize the distribution. In all instances $\mathrm{P}<0.05$ if $r>0.25$.

This is the Pearson product moment (parametric) correlation coefficient obtained in correlating the FFQ-derived nutrient score with the equivalent $24 \mathrm{HR}$-derived nutrient score.

gender revealed no clear pattern by sex (results not shown in table form); about half the time the coefficient was closer to 1.0 for men. The intraclass correlation coefficient by household averaged 0.36 for the baseline FFQ, 0.26 for the 1-year FFQ and 0.58 for the average of the eight $24 \mathrm{HR}$.

Table 3 also shows the results of the linear regression model obtained by regressing nutrient scores derived from the FFQ at baseline and the FFQ after 1 year with those derived from the eight $24 \mathrm{HR}$. As for the correlation analyses, there was no clear pattern by gender.

\section{Discussion}

This article represents the first description of an FFQ developed and tested in India. The purpose of the FFQ is to provide quantitative assessment of nutrient exposures for use in an epidemiological study. In designing the dietary assessment methodology for this study of diet and oral precancerous lesions in India, it was hypothesized that the FFQ would be most appropriate for this purpose. Compared to our studies in the $\mathrm{USA}^{21}$, relatively few foods constitute the vast majority of total dietary intake. The sequelae might be relatively little bias in recall due to cognitive or memory-related problems $s^{30-33}$. Previously we found that subjects in this population appeared to be skilled in estimating the weights and volumes of commonly used foods?. Usually, FFQs in the West are selfadministered and semi-quantitative in terms of estimation of usual portion size $e^{1,4,5}$. Because a proportion of the study population was illiterate, this FFQ was interviewer-administered. The interviewer also obtained quantitative estimates of the weight or volume of the food item consumed.

Overall, the results from this study are broadly consistent with those reported on FFQs in Western populations. Pearson correlation coefficients averaged around 0.50 in the comparison with the FFQ at baseline and around 0.55 in the analysis based on the 1-year comparisons. Unlike a comparison of a pre- and post-7 day diet recalls (7DDR) which showed better agreement in the post-comparisons ${ }^{21}$, there was no such pattern in this study. In that study, the 7DDRs were administered only 3 weeks apart, with 7 days of $24 \mathrm{HR}$ administered in the interval. Therefore, the 7 days represented one-third of the total and the 'training' occurred over a much shorter period. Also, the 7DDR was self-administered.

In analyses of these data, the Spearman rank correlation coefficients were slightly higher than the Pearson product moment correlations, indicating that this FFQ was superior at rank ordering individuals, the normal use of such data in most epidemiological studies. The fact that the nutrient scores derived from the FFQ administered at the beginning of the interval agreed with the $24 \mathrm{HR}$-derived scores about as well as did the post-FFQ scores is encouraging because it is only the first FFQ to which the typical epidemiological study normally would have access.

Regression coefficients were closer to 1.0 in the analyses comparing the $24 \mathrm{HR}$-derived scores with those from the baseline FFQ. Six coefficients were significantly different from 1.0. However, in comparing 
data derived from the 1-year FFQ with the 24HR data, only two regression coefficients were consistent with $\mathrm{H}_{\mathrm{o}}: \beta=1.0$. In some instances, difference scores were very large, especially in comparison to the first FFQ. So, even in instances where linear and rank order agreement were good there were some large differences in the point estimates of the nutrient scores.

The first and second FFQ administrations differed from each other in a number of important ways. The first administration, because it preceded any of the $24 \mathrm{HR}$, did not focus on a time frame that corresponded to exposure as estimated by the eight $24 \mathrm{HR}$. Most epidemiological studies (including the one for which this FFQ was developed) would have access to only one FFQ for any aetiologically relevant period. An implicit assumption is made that diet is stable enough over long periods of time so that FFQs administered a year or more apart ought to yield the same results for most subjects. Seasonal variability may be large, especially in a place such as Kerala, but the two FFQs were administered in exactly the same season, a year part. Although the second FFQ focused on the same time period as the eight $24 \mathrm{HR}$, perhaps it also benefited from the training provided by all the assessments conducted in the interim, including the first FFQ.

In most epidemiological studies the intent is to estimate relative risk between levels of exposure within the study group and health-related endpoints. Therefore, good linear agreement and, more importantly, rank order agreement (because the data usually are expressed as quantiles) is required. The fact that the differences between the FFQ and 24HR data were larger for the first FFQ would be of greater concern in circumstances where the intent is to make specific recommendations regarding actual (and not relative) nutrient exposures in individuals. Since there was good linear and rank order agreement between nutrient scores derived from this FFQ and those derived from the $24 \mathrm{HR}$, it is concluded that it is as well suited for the purposes of estimating risk in epidemiological studies as those FFQs commonly used in the West.

\section{Acknowledgements}

This work was supported by the Special Foreign Currency Program of the Fogarty International Center (National Institutes of Health) grant number N-406-645 and a USIA Fulbright Senior Research Fellowship to Dr James R. Hebert for the 1997-8 academic year through the US Educational Foundation in India.

\section{References}

1 Willett WC. Nutritional Epidemiology. Oxford: Oxford University Press 1990.
2 Hebert JR, Miller DR. Methodologic considerations for investigating the diet-cancer link. Am. J. Clin. Nutr. 1988; 47: 1068-77.

3 Hebert JR, Clemow L, Pbert L, Ockene IS, Ockene JK. Social desirability and approval biases in dietary self-report may profoundly compromise the validity of diet-disease studies. Int. J. Epidemiol. 1995; 24: 389-98.

4 Willett WC, Sampson L, Stampfer MJ, et al. Reproducibility and validity of a semiquantitative food frequency questionnaire. Am. J. Epidemiol. 1985; 122: 51-65.

5 Block G, Woods M, Potosky A, Clifford C. Validation of a self-administered diet history questionnaire using multiple diet records. J. Clin. Epidemiol. 1990; 43: 1327-35.

6 Chadha SL. Dietary profile of adults in an urban and a rural community. Indian J. Med. Res. 1995; 101: 258-67.

7 Rao, B. Monitoring nutrient intakes in India. Indian J. Pediatr. 1987; 54: 495-501.

8 National Institute of Nutrition (NIN). National Nutrition Monitoring Bureau Report of Repeat Surveys (1988-90). Indian Council of Medical Research. Hyderabad, India: NIN, 1991.

9 Hebert JR, Gupta PC, Bhonsle R et al. Determinants of accuracy in estimating the weight and volume of commonly used foods: a cross-cultural comparison. Ecology of Food and Nutrition (submitted for publication)

10 Sankaranarayanan $R$, Varghese C, Duffy SW, Padmakumary G, Day NE, Nair MK. A case-control study of diet and lung cancer in Kerala, south India. Int. J. Cancer 1994; 58: 644-9.

11 Nandakumar A, Thimmasetty KT, Sreeramareddy NM, et al. A population-based case-control investigation on cancers of the oral cavity in Bangalore, India. Br. J. Cancer 1990; 62: $847-51$.

12 Notani PN. Role of diet and alcohol in tobacco-related cancer at sites in the upper aerodigestive tract in an Indian population. In: Gupta PC, Hamner JE, Murti PR, eds. Control of Tobacco-Related Cancers and Other Diseases: Proceedings of an International Symposium: 15-19 January 1990. Bombay, India: Oxford University Press, 1990; 149-55.

13 Gupta PC, Bhonsle RB, Murti PR, Daftary DK, Mehta FS, Pindborg JJ. An epidemiologic assessment of cancer risk in oral precancerous lesions in India with special reference to nodular leukoplakia. Cancer 1989; 63: 2247-52.

14 National Institute of Nutrition (NIN). Nutritive Value of Indian Foods. Hyderabad, India: NIN, 1993.

15 Messer E. Intra-household allocation of food and health care: current findings and understandings - introduction. Soc. Sci. Med. 1997; 44: 1675-84.

16 Hebert JR. Relationship of vegetarianism to child growth in South India. Am. J. Clin. Nut. 1985; 42: 1246-54.

17 Thimmayamma B. A Handbook of Schedules and Guidelines in Socio-economic and Diet Surveys. Hyderabad, India: National Institute of Nutrition, 1987.

18 Gibson RS. Principles of Nutritional Assessment. New York: Oxford University Press, 1990.

19 Hebert JR, Miller DR, Barone J, Engle A. Assessment of Change in Fat Intake in an Intervention Study. American Public Health Association (APHA), 119th Annual Meeting. Atlanta, GA: APHA, 1991.

20 Posner BM, Martin-Munley SS, Smigelski C, et al. Comparison of techniques for estimating nutrient intake: the Framingham Study. Epidemiology 1992; 3: 171-7.

21 Hebert JR, Ockene IS, Hurley TG, Luippold R, Well AD, Harmatz MG. Development and testing of a seven-day dietary recall. J. Clin. Epidemiol. 1997; 50: 925-37.

22 Franke RW, Chasin BH. Kerala State, India: radical reform as development (Review). Int. J. Healtb Serv. 1992; 22: 139-56.

23 Neff $\mathrm{D}$. The social construction of infertility: the case of the matrilineal Nayars in south India. Soc. Sci. Med. 1994; 339: 475-85. 
24 Rosner B, Willett WC. Interval estimates for correlation coefficients corrected for within-person variation: implications for study design and hypothesis testing. Am. J. Epidemiol. 1988; 127: 377-86.

25 Salvini S, Hunter DJ, Sampson L, et al. Food-based validation of a dietary questionnaire: the effects of week-to-week variation in food consumption. Int. J. Epidemiol 1989; 18: 858-67.

26 Hebert JR, Miller DR. The inappropriateness of conventional use of the correlation coefficient in assessing validity and reliability of dietary assessment methods. Euro. J. Epidemiol. 1991; 7: 339-43.

27 Borrelli R, Cole TJ, DiBiase G, Contaldo F. Some statistical considerations on dietary assessment methods. Eur. J. Clin Nutr. 1989; 43: 453-63.

28 Bland JM, Altman DG. Statistical methods for assessing agreement between two methods of clinical measurement. Lancet 1986; i: 307-10.

29 Dasgupta P. An Inquiry into Well-Being and Destitution. Oxford: Oxford University Press, 1995.

30 Jobe JB, Mingay DJ. Cognitive research improves questionnaires. Am. J. Publ. Healtb 1989; 79: 1053-5.

31 Dwyer JT, Gardner J, Halvorsen K, Krall EA, Cohen A Valadian I. Memory of food intake in the distant past. Am.J. Epidemiol. 1989; 130: 1033-46.

32 Smith AF. Cognitive psychological issues of relevance to the validity of dietary reports. Eur. J. Clin. Nutr. 1993; 47(suppl 2): S6-S18

33 Dwyer JT, Coleman KA. Insights into dietary recall from a longitudinal study: accuracy over four decades. Am. J. Clin. Nutr. 1997; 65: 1153S-8S. 